\title{
Measuring droplet fall speed with a high-speed camera: indoor accuracy and potential outdoor applications
}

\author{
Cheng-Ku Yu ${ }^{1}$, Pei-Rong Hsieh ${ }^{1}$, Sandra E. Yuter ${ }^{2}$, Lin-Wen Cheng ${ }^{1}$, Chia-Lun Tsai ${ }^{1}$, Che-Yu Lin ${ }^{3}$, and Ying Chen ${ }^{1}$ \\ ${ }^{1}$ Department of Atmospheric Sciences, National Taiwan University, Taipei, Taiwan \\ ${ }^{2}$ Department of Marine, Earth, and Atmospheric Sciences, North Carolina State University, Raleigh, North Carolina, USA \\ ${ }^{3}$ Department of Atmospheric Sciences, Chinese Culture University, Taipei, Taiwan \\ Correspondence to: Cheng-Ku Yu (yuku@ntu.edu.tw)
}

Received: 17 December 2015 - Published in Atmos. Meas. Tech. Discuss.: 18 January 2016

Revised: 1 April 2016 - Accepted: 13 April 2016 - Published: 22 April 2016

\begin{abstract}
Acquisition of accurate raindrop fall speed measurements outdoors in natural rain by means of moderatecost and easy-to-use devices represents a long-standing and challenging issue in the meteorological community. Feasibility experiments were conducted to evaluate the indoor accuracy of fall speed measurements made with a high-speed camera and to evaluate its capability for outdoor applications. An indoor experiment operating in calm conditions showed that the high-speed imaging technique can provide fall speed measurements with a mean error of 4.1-9.7\% compared to Gunn and Kinzer's empirical fall-speed-size relationship for typical sizes of rain and drizzle drops. Results obtained using the same apparatus outside in summer afternoon showers indicated larger positive and negative velocity deviations compared to the indoor measurements. These observed deviations suggest that ambient flow and turbulence play a role in modifying drop fall speeds which can be quantified with future outdoor high-speed camera measurements. Because the fall speed measurements, as presented in this article, are analyzed on the basis of tracking individual, specific raindrops, sampling uncertainties commonly found in the widely adopted optical disdrometers can be significantly mitigated.
\end{abstract}

\section{Introduction}

Droplet fall speed (DFS) is an important microphysical parameter playing a key role in modulating precipitation distributions within three-dimensional storm structures and surface rainfall rates (Rogers and Yau, 1989; Houze Jr., 1993; Yu and Cheng, 2008; Parodi and Emanuel, 2009; Yu and
Cheng, 2013). For radar-related and modeling applications, DFS is usually approximated by the so-called "terminal velocity" $\left(V_{\mathrm{t}}\right)$, the relative velocity of an object to the air when the aerodynamic drag force exactly balances the gravitational force. Practically, $V_{\mathrm{t}}$ may be considered to have a simple one-to-one relationship with raindrop size, and this relationship has been well described in both theoretical and observational frameworks (Gunn and Kinzer, 1949; Atlas et al., 1973; Beard, 1976; Doviak and Zrnić, 1993). Environmental conditions associated with natural rainfall events are typically characterized by turbulent air motions and by a population of falling drops with various sizes. The inertial acceleration of droplets responding to various combinations of wind, turbulence, collision, and breakup may yield appreciable departures of DFS from $V_{\mathrm{t}}$ (Pinsky and Khain, 1996; Pruppacher and Klett, 1997; Montero-Martínez et al., 2009). Nevertheless, our understanding of the degree to which the theoretical value of $V_{\mathrm{t}}$ corresponds to the natural DFS has been rather limited due to the great challenge of measuring accurate values of DFS in natural conditions outdoors over a wide spectrum of drop sizes and environments.

In the past century, significant efforts have been made by many researchers to explore a number of different methods for measuring DFS. Lenard (1904) estimated $V_{\mathrm{t}}$ indirectly by measuring the velocity of the air blast by which droplets could be suspended in the air stream. Such suspension techniques were later used to document the behavior of raindrops falling at $V_{\mathrm{t}}$ in many wind-tunnel studies (Blanchard, 1950; Cotton and Gokhale, 1967; Pruppacher and Pitter, 1971). Other, earlier studies measured DFS by employing shutter and stroboscopic devices (Schmidt, 1909; Laws, 
1941). However, these older investigations had large uncertainties in the measurement of drop size, which were estimated using absorbent paper or highly refined flour methods.

A more sophisticated "electronic method" was developed in the 1940s which measured the free fall speed of artificially generated raindrops inside a laboratory and/or a rain shaft (Wang and Pruppacher, 1977). Gunn and Kinzer (1949) (hereafter GK) employed this method to measure $V_{\mathrm{t}}$ in stagnant air by determining the time between the two pulses generated as an electrically charged droplet fell through two inducing rings separated by a known distance. Together with the careful determination of drop size using a weighting method and a microscope, GK were able to provide accurate measurements of $V_{\mathrm{t}}$ over a wide range of drop sizes. The velocity and size measurements described by GK represent a very reliable reference for theoretical magnitudes of $V_{\mathrm{t}}$ in a standard atmosphere at $20^{\circ} \mathrm{C}$ and $1013 \mathrm{mb}$ and have been widely used. The methodology employed by GK and in similar studies requires a specially designed apparatus operating in a highly controlled environment and is ill-suited for outdoor measurements.

Advancements in photoelectronic techniques since the 1970s have increased the possibilities of measuring DFS associated with natural rainfall events. A growing number of optical instrument types have been proposed in the literature, such as the spectropluviometer (Donnadieu, 1980; Hauser et al., 1984), the particle size and velocity disdrometer (PARSIVEL; Löffler-Mang and Joss, 2000), the two-dimensional video disdrometer (2DVD; Schönhuber et al., 1997; Thurai et al., 2013), the Hydrometeor Velocity and Shape Detector (HVSD; Barthazy et al., 2004), and the Multi-Angle Snowflake Camera (MASC; Garrett et al., 2012). The basic physical principles underlying these optical instruments are quite similar, with drop size estimated by the degree to which a light sheet is blocked and velocity determined based on the duration of blocking occurrence or the time required to pass through a pair of vertically separate light sheets. Optical disdrometers are designed for outdoor use and can measure simultaneous size and velocity information automatically. Nevertheless, the accuracy of these instrumental measurements is frequently hampered not only by a variety of sampling uncertainties, such as the splash contamination, margin fallers, and coexistence of two particles inside the light sheet (Löffler-Mang and Joss, 2000; Kruger and Krajewski, 2002; Yuter et al., 2006; Niu et al., 2010), but also by the assumptions implicit in the algorithms required to automatically determine drop sizes and velocities (Battaglia et al., 2010; Friedrich et al., 2013). In addition, most of these optical disdrometers cannot distinguish sizes within a size interval (known as the quantization error) and usually suffer from poor signal quality for submillimeter drops (LöfflerMang and Joss, 2000; Yuter et al., 2006). Drop shape deformation and oscillation that usually occur for larger raindrops (diameters $>\sim 1 \mathrm{~mm}$ ) (e.g., Testik et al., 2006) represent an- other important uncertainty regarding the accuracy of these optical disdrometers.

Another group of instruments for retrieving DFS is called the optical array spectrometer probes, as adopted in MonteroMartínez et al. (2009) to study natural DFSs under conditions of weak ambient winds. Horizontal and vertical extent of the two-dimensional image produced as drops fall past a linear diode array were used to estimate the drop diameter and fall speed, respectively. This methodology involves a theoretical approximation of drop shape deformation for size and velocity determination, as well as possible sampling uncertainties such as those usually found in the aforementioned optical disdrometers. These inherent limitations similarly cause lower precision in the DFS measurement.

An intuitive way of measuring DFS across a wide range of drop sizes is to use a high-speed camera (hereafter HSC) that acquires a set of images of the same particle with adequate spatial and temporal resolution to permit clear identification of its shape and position. A HSC has been used to investigate the behavior of raindrop oscillations and the impact of water drops on the Earth's surface, as described in a number of articles (Fukada and Fujiwara, 1989; Ghadiri, 2006; Testik et al., 2006; Licznar et al., 2008; Szakáll et al., 2010). However, these HSC published works did not address the possible application of the HSC to the investigation of atmospheric DFSs. The primary objective of this study is to determine the degree of accuracy of DFS measurements made with a HSC and to further understand its potential for measuring DFSs in the outdoor environment. Photographed images of artificially created, freely falling water drops of various sizes (diameters from $\sim 0.2$ to $\sim 3 \mathrm{~mm}$ ) from an indoor experimental work were first analyzed to calculate DFS values. The calculated DFS were then compared with theoretical values of $V_{\mathrm{t}}$ to provide quantitative evaluation for the velocity measurement obtained from the HSC. A set of outdoor experiments were also undertaken to evaluate the capability of a HSC to study DFSs associated with natural rainfall events.

\section{Instruments and indoor experimental settings}

The indoor experiment was conducted in the interior staircase of the Ta-Shiao building located within the campus of the Chinese Culture University (CCU), Taipei, in June 2012. The instruments and experimental settings used are illustrated schematically in Fig. 1. The key instrument for the experiment was a HSC with a $400 \mathrm{~mm}$ lens focal length, operated with a recording frame rate of $3600 \mathrm{fps}$ and a shutter speed of $50000 \mathrm{~s}^{-1}$. To improve the spatial resolution of photographed images, two extension tubes were mounted with the lens, resulting in a view frame of approximately $29 \times 29 \mathrm{~mm}^{2}$ (corresponding to $1024 \times 1024$ pixels) and a focal plane at a distance of $\sim 106 \mathrm{~cm}$ from the lens. In this setting, the pixel size was quite small, approximately $0.028 \times 0.028 \mathrm{~mm}^{2}$, allowing for better identification of the outline and shape for the typical sizes of rain and drizzle 


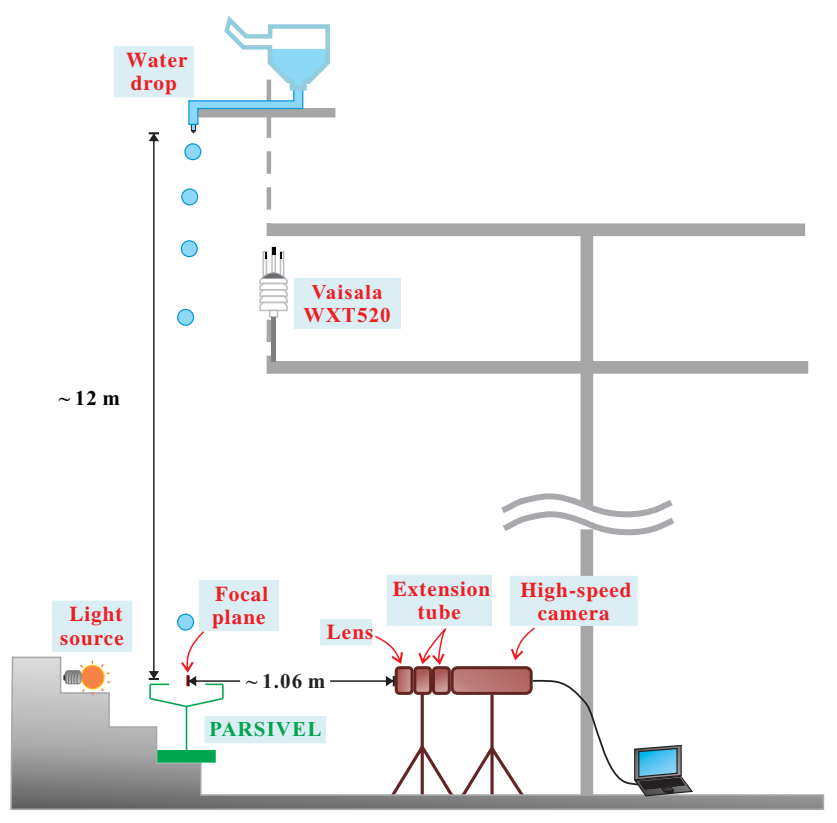

Figure 1. Instruments and experimental settings adopted for the present study (see text for details).

drops. A portable computer installed with image processing software was connected to the HSC, providing a real-time recording and visualization of the photographed water drops.

In this study, hypodermic needles with various pinhole sizes and the sprinkling method (Magono et al., 1963) were used to generate large $(>\sim 2 \mathrm{~mm})$ and small $(<\sim 2 \mathrm{~mm})$ water drops, respectively. The artificially created water drops were released at a distance of $\sim 12 \mathrm{~m}$ above the camera. This distance is close to the theoretical and experimental prediction of the distance required for large drops (greater than $2 \mathrm{~mm}$ ) to reach the $V_{\mathrm{t}}$ from rest under atmospheric conditions of $1000 \mathrm{mb}$ and $20^{\circ} \mathrm{C}$ (Wang and Pruppacher, 1977). However, the laboratory simulations from a recent study of Chowdhury et al. (2016) have also shown that the required fall distances to reach the $V_{\mathrm{t}}$ are slightly smaller than the theoretical values, with $\sim 7$ (10) $\mathrm{m}$ for a drop size of 2.6 (3.7) $\mathrm{mm}$. These results suggest that the fall distance in our experimental setup should be adequate for studying the $V_{\mathrm{t}}$. The bright-field illumination technique (Cannon, 1970; Jones et al., 2003; Testik et al., 2006), provided by a light source standing in front of the lens (Fig. 1), was used to produce a bright background and a dark drop silhouette. Because of the high recording rate and inherent limitation of storage memory, only a very short duration of $\sim 1.5 \mathrm{~s}$ (corresponding to $\sim 5400$ frames) was used for each recorded period. The images obtained during each recorded period were then checked visually to select particular water drops with a distinct and well-defined shape and outline. Blurred images of water drops that fell outside the focal zone $(1-1.5 \mathrm{~cm})$ were excluded from this study. The recorded images from a total of 95 water drops in the focal plane with a range of diameters
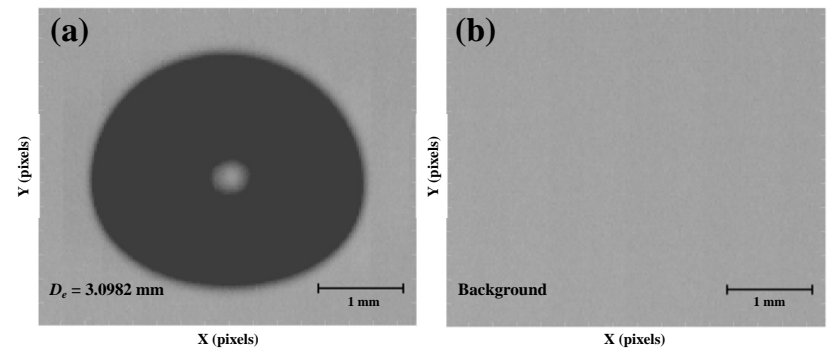

Figure 2. (a) Sample image of a water drop photographed using a high-speed camera. The drop appears as a dark area, and the small, brighter area near the drop center is due to the bright-field illumination adopted in this study. (b) Corresponding background image taken just before the drop fell into the view frame of the lens.

from $\sim 0.2$ to $\sim 3 \mathrm{~mm}$ were collected for subsequent velocity and size analysis.

Other instruments employed in the indoor experiment are a PARSIVEL disdrometer and a lightweight Vaisala weather transmitter (WXT520). The PARSIVEL disdrometer was situated between the light source and lens, with its sensing area roughly collocated with the focal plane. The primary purpose of deploying this optical instrument was to provide independent measurements for initial comparisons with the DFS values measured by the HSC. The thermodynamic and wind conditions within the experimental room were automatically monitored by a WXT520 sensor mounted at a height of $\sim 9 \mathrm{~m}$ above the floor. The measurements taken during the collection of the analyzed images indicate a nearly calm condition (a mean wind speed of $0.07 \mathrm{~m} \mathrm{~s}^{-1}$ ) with average temperature, pressure, and relative humidity equal to $30.2^{\circ} \mathrm{C}, 956.4 \mathrm{mb}$, and $53 \%$, respectively.

\section{Determination of drop size and velocity}

Under bright-field illumination the photographed water drops appear in the recorded image as a darker area. Figure 2 shows a sample image of a photographed water drop and its corresponding background image taken just before it fell into the view frame of the lens. There was a sharp transition from light gray to darker gray pixels near the surface of the water drop (Fig. 2a), yielding a pronounced gradient of brightness values ${ }^{1}$ characterizing the outline region. Near the drop center there were also some changes in brightness, related to the bright-field illumination adopted in this study.

To determine the drop outline, we consider both the brightness difference between the lighter background (Fig. 2b) and the darker drop (Fig. 2a) and the local gradient of brightness. The brightness gradient was determined using the fourconnected pixels in the vertical and horizontal. Both brightness difference and brightness gradient were calculated for each pixel in each image containing a water droplet. The

\footnotetext{
${ }^{1}$ The range of the brightness values is from 0 (black) to 255 (white).
} 


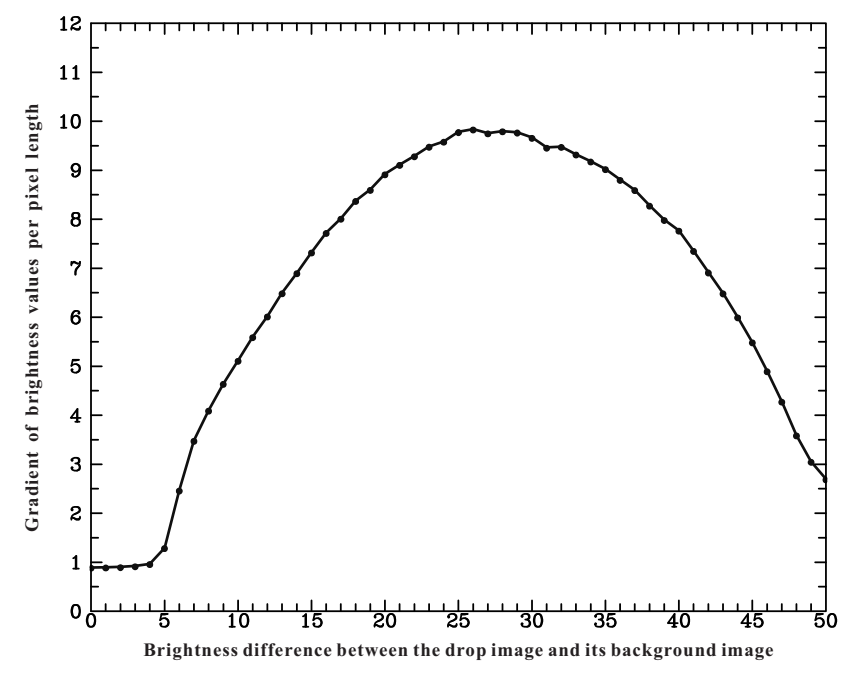

Figure 3. Statistical relationship between the gradient of brightness values per pixel length (ordinate) and the difference in the brightness values between the drop image and its corresponding background image (abscissa) calculated from all recorded images of 95 water drops collected from the indoor experiment.

mean gradient values averaged within each interval of brightness difference and plotted as a function of brightness differences are shown in Fig. 3. The analysis indicates that a welldefined threshold value of brightness difference coinciding with the peak gradient of brightness, presumably marking the drop surface, is approximately equal to 26 .

With the brightness characteristics of the drop images described above, two objective methods may be used to determine the drop size. The first method was to calculate the brightness difference between the drop and its background image for each pixel within the view frame and to mark the drop area of the pixels with the threshold of 26 as described above. Once the two-dimensional drop outline was obtained, the drop volume (vol) was calculated with an integration technique by summing the volumes of threedimensional disks with thickness and diameter corresponding to the height of one pixel and each horizontal pixel row, respectively, as described in Jones and Saylor (2009). The equivalent diameter of the drop (hereafter $D_{\mathrm{e}}$ ) could be derived directly from the calculated drop volume through the formula $D_{\mathrm{e}}=(6 \mathrm{vol} / \pi)^{1 / 3}$. It is noteworthy that, if we use 24 or 28 as a threshold (cf. Fig. 3), it causes a rather minor difference in the drop size (within $1.5 \%$ ) compared to that using the threshold value of 26 . The determination of the drop size is not very sensitive to the threshold we choose. The second method used a procedure similar to the first, except that the drop outline was adaptively determined by the peak value of brightness gradient found along each radial direction from the drop center.

Figure 4 illustrates the objectively determined drop outlines and their corresponding diameters for three differ-
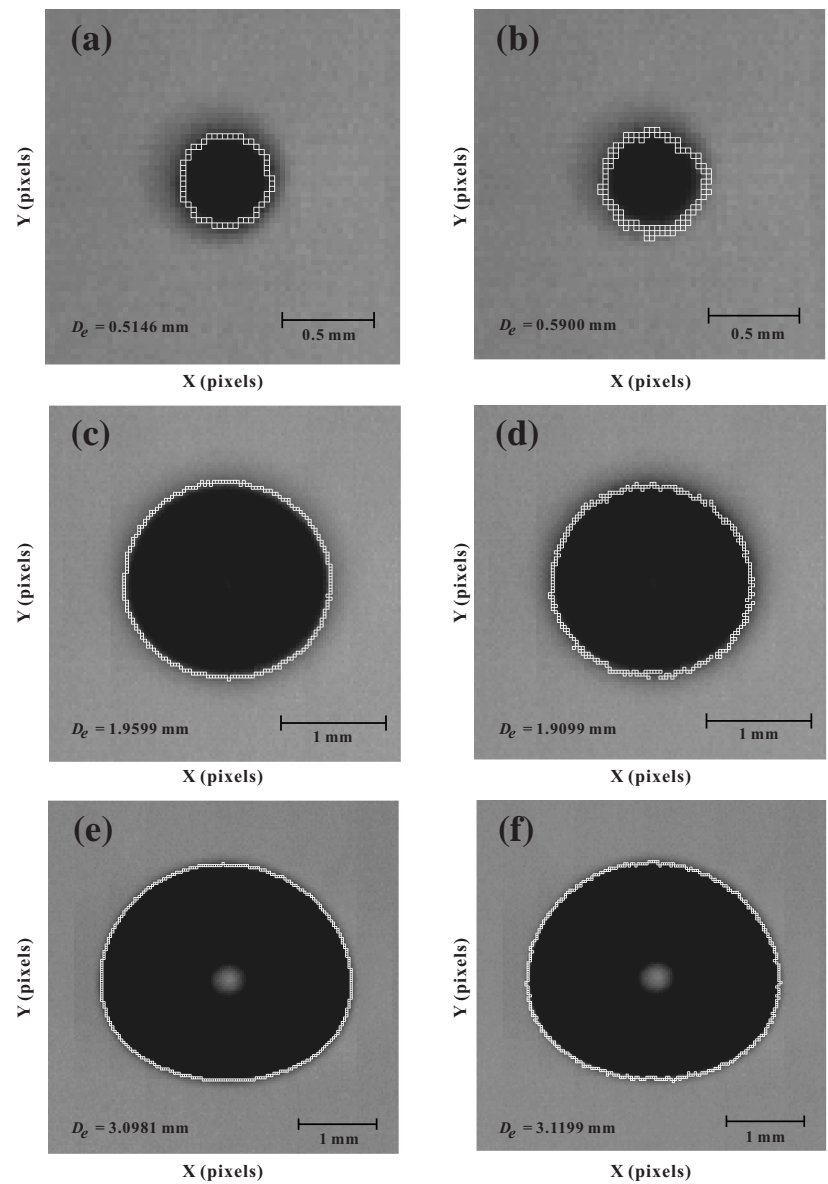

Figure 4. Drop outlines for three different sizes of water drops (small, medium, and large) determined objectively by the difference in brightness value between the drop image and its background image (a, c, e) and by the gradient of brightness along the radial direction from the drop center $(\mathbf{b}, \mathbf{d}, \mathbf{f})$. Equivalent diameter of the drop $\left(D_{\mathrm{e}}\right)$ derived from the determined drop outline is also indicated in each panel.

ent water drop sizes. For medium $\left(D_{\mathrm{e}}=1.9 \mathrm{~mm}\right)$ and large $\left(D_{\mathrm{e}}=3.0 \mathrm{~mm}\right)$ water drops, the drop outlines and equivalent diameters determined by the two methods were nearly identical (i.e., within $2.5 \%$, Fig. 4c-f). For the small $\left(D_{\mathrm{e}}=0.5 \mathrm{~mm}\right)$ water drop, the difference in $D_{\mathrm{e}}$ between the two methods became larger $(\sim 15 \%)$ (Fig. $4 a, b)$. A smoother, reasonable drop surface was obtained with the brightness difference (Fig. 4a). In contrast, the criterion using the radial gradient of brightness value yielded a clear deviation of the drop outline from a spherical shape (Fig. 4b), which is obviously not realistic given the small size of the drop (i.e., $\sim 0.5 \mathrm{~mm}$ ). In fact, experience indicates that this method generally has a larger potential uncertainty in determining the size of small drops because the brightness contrast across their outline is usually less distinct. In view of this limitation, the criterion based on the single threshold brightness difference between the drop image and its back- 
ground image was adopted for size determination in this study. For a given water drop, there were a number of photographed images within the view frame and a representative size was then obtained by averaging sizes from all in focus images. It is noteworthy that the method of detecting drop outline is generally not a key factor to influence the accuracy of size determination. Instead, relative dimension of the pixel size (i.e., image resolution) and drop size is more critical for the size determination. Given the pixel size of $0.028 \mathrm{~mm}$, the minimum resolvable length for the drop image, it is reasonable to consider a potential uncertainty for determining each horizontal pixel row of the drop equal to \pm 2 pixels. To obtain a maximum (minimum) possible drop size, all of the horizontal pixel rows constituting the drop are increased (decreased) with 2 pixels when integrating the drop volume from each horizontal pixel row. A range of size error may be evaluated by calculating the deviation of the originally estimated drop size from the calculated maximum/minimum drop size, which is equal to $\pm 0.040-0.045 \mathrm{~mm}$.

Drop velocity can be measured directly with the HSC by simply tracking the moving water drop within the view frame in a sequence of images. The geometric center of the drop for each of the instantaneous images was first determined by calculating the mean spatial coordinate of all pixels constituting the drop. Figure 5 shows a sample plot produced by compositing multiple sequences of drop images and their corresponding geometric centers. In principle, a drop's velocity can be calculated by the distance between the geometric centers from two successive or arbitrary drop images divided by their recorded time difference. However, we consider a specific distance between the highest and lowest geometric centers of the photographed in focus water drop (i.e., $d$ in Fig. 5) identified within the view frame and the corresponding duration. A mean, representative drop velocity can be obtained by this calculation. It is noteworthy that the uncertainty of determining the geometric center of the drop due to the limitation of pixel resolution would mostly come from the positions of pixels constituting the drop outline instead of those interior pixels of the drop. Assuming that all pixels constituting the drop outline have a position error of the pixel size, the potential error in the drop's position may be approximated by multiplying the pixel size (i.e., $0.028 \mathrm{~mm}$ ) by the ratio of the number of pixels within the drop outline and the number of pixels in the area of the entire drop because the geometric center of a drop is determined by a mean spatial coordinate of all pixels constituting the drop. For example, the ratio and the position errors for the larger drop shown in Fig. 5 were calculated to be $\sim 0.022$ and $\sim 0.0006 \mathrm{~mm}$. With a recording frame rate of $3600 \mathrm{fps}$ adopted in this study, the position error yields a velocity error of $\sim 0.002 \mathrm{~m} \mathrm{~s}^{-1}$. For the size range of the studied drops, the ratio ranges from 0.02 to 0.38 . This gives a position error of $0.00056-0.01064 \mathrm{~mm}$, corresponding to a velocity error of $0.002-0.038 \mathrm{~m} \mathrm{~s}^{-1}$. These velocity errors due to pixel resolution are much smaller than the ve-

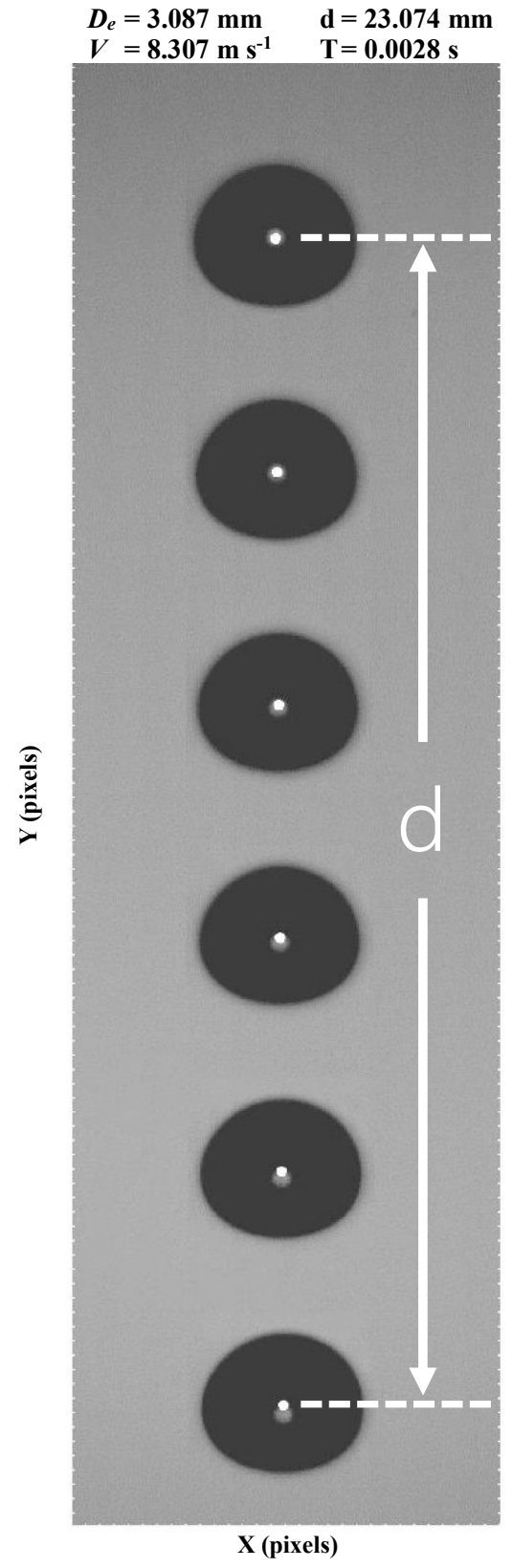

Figure 5. Multiple sequences of the photographed images as a sample water drop fell into the view frame of HSC. White dots indicate corresponding geometric center of the drop at different time. The vertical distance between the highest and lowest geometric center within the view frame is indicated by " $d$ ".

locity uncertainties related to the size determination as will be discussed in Sect. 5 .

\section{Theoretical $V_{t}$}

The accuracy of DFSs measured by the HSC using the indoor experimental setup is evaluated by comparing with the $V_{\mathrm{t}^{-}}$ 
Table 1. Velocity deviations (i.e., $V_{\mathrm{e}}$ ) of 29 analyzed drops collected from the outdoor experiments and ambient conditions including horizontal wind speed $\left(W_{\mathrm{S}}\right)$, vertical air motions $\left(W_{\text {air }}\right)$, turbulent kinetic energy (TKE), and rainfall rate $(R)$ corresponding to each analyzed drop. Rain rates were measured by the Vaisala weather transmitter (WXT520).

\begin{tabular}{|c|c|c|c|c|c|c|c|c|c|}
\hline $\begin{array}{c}\text { Drop } \\
\text { no. }\end{array}$ & (YYMMD & $\begin{array}{l}\text { ne } \\
\text { HHMMSS) }\end{array}$ & $\begin{array}{r}D_{\mathrm{e}} \\
(\mathrm{mm})\end{array}$ & $\begin{array}{r}V_{\mathrm{e}} \\
\left(\mathrm{m} \mathrm{s}^{-1}\right)\end{array}$ & $\begin{array}{r}V_{\mathrm{e}} \\
(\%)\end{array}$ & $\begin{array}{r}W_{\mathrm{S}} \\
\left(\mathrm{m} \mathrm{s}^{-1}\right)\end{array}$ & $\begin{array}{r}W_{\text {air }} \\
\left(\mathrm{m} \mathrm{s}^{-1}\right)\end{array}$ & $\begin{array}{r}\text { TKE } \\
\left(m^{2} s^{-2}\right)\end{array}$ & $\begin{array}{r}R \\
\left(\mathrm{~mm} \mathrm{~h}^{-1}\right)\end{array}$ \\
\hline 1 & 130815 & 141645 & 0.2286 & -0.19 & -22.34 & 0.3 & -0.1 & 0.0 & 5.3 \\
\hline 2 & 140625 & 151303 & 0.2596 & 0.22 & 21.94 & 1.2 & -0.7 & 1.6 & 94.7 \\
\hline 3 & 140625 & 151303 & 0.3510 & -0.21 & -14.78 & 1.2 & -0.7 & 1.6 & 94.7 \\
\hline 4 & 130815 & 141238 & 0.4204 & 0.26 & 14.93 & 0.3 & 0.1 & 0.2 & 3.6 \\
\hline 5 & 140625 & 151303 & 0.4233 & 0.32 & 18.20 & 1.2 & -0.7 & 1.6 & 94.7 \\
\hline 6 & 130815 & 145817 & 0.6172 & 0.11 & 4.35 & 0.8 & 0.0 & 0.2 & 0.8 \\
\hline 7 & 130815 & 145511 & 0.7001 & -0.39 & -13.19 & 0.5 & -0.1 & 0.5 & 0.9 \\
\hline 8 & 140625 & 164225 & 0.7222 & -0.05 & -1.54 & 0.6 & -0.2 & 0.1 & 0.5 \\
\hline 9 & 140625 & 160243 & 0.7231 & -0.53 & -17.22 & 0.7 & -0.3 & 0.3 & 0.0 \\
\hline 10 & 140625 & 171849 & 0.8174 & -0.13 & -3.79 & 1.2 & -0.2 & 0.4 & 0.1 \\
\hline 11 & 140625 & 151303 & 0.8987 & 0.31 & 8.29 & 1.2 & -0.7 & 1.6 & 94.7 \\
\hline 12 & 140625 & 164225 & 0.9237 & 0.02 & 0.45 & 0.6 & -0.2 & 0.1 & 0.5 \\
\hline 13 & 140625 & 155949 & 0.9488 & -1.17 & -29.58 & 2.1 & -0.1 & 1.9 & 0.3 \\
\hline 14 & 140625 & 151303 & 0.9523 & 0.23 & 5.85 & 1.2 & -0.7 & 1.6 & 94.7 \\
\hline 15 & 140625 & 155637 & 0.9589 & -0.33 & -8.36 & 1.2 & -0.3 & 1.2 & 3.2 \\
\hline 16 & 130815 & 150104 & 0.9738 & -0.11 & -2.68 & 0.5 & 0.2 & 0.1 & 0.6 \\
\hline 17 & 130815 & 135706 & 1.1254 & -0.08 & -1.87 & 0.6 & 0.1 & 0.0 & 0.8 \\
\hline 18 & 140625 & 151303 & 1.1430 & -0.01 & -0.11 & 1.2 & -0.7 & 1.6 & 94.7 \\
\hline 19 & 130815 & 142202 & 1.2000 & -0.43 & -9.10 & 0.2 & 0.2 & 0.0 & 6.0 \\
\hline 20 & 130815 & 140332 & 1.2120 & -0.34 & -7.03 & 1.2 & 0.0 & 0.0 & 2.4 \\
\hline 21 & 140625 & 151303 & 1.2138 & 0.34 & 7.05 & 1.2 & -0.7 & 1.6 & 94.7 \\
\hline 22 & 130815 & 140332 & 1.2475 & -0.33 & -6.71 & 1.2 & 0.0 & 0.0 & 2.4 \\
\hline 23 & 130815 & 140818 & 1.5661 & -0.58 & -10.15 & 0.3 & 0.2 & 0.1 & 3.2 \\
\hline 24 & 130815 & 140818 & 1.9251 & -0.67 & -10.27 & 0.3 & 0.2 & 0.1 & 3.2 \\
\hline 25 & 130815 & 144018 & 1.9774 & -0.39 & -5.92 & 1.2 & -0.5 & 0.5 & 5.3 \\
\hline 26 & 140625 & 151303 & 1.9844 & 0.32 & 4.83 & 1.2 & -0.7 & 1.6 & 94.7 \\
\hline 27 & 130815 & 141645 & 2.1361 & -0.33 & -4.76 & 0.3 & -0.1 & 0.0 & 5.3 \\
\hline 28 & 140625 & 155222 & 3.3562 & -0.25 & -2.86 & 0.6 & 0.1 & 0.6 & 48.7 \\
\hline 29 & 140625 & 151303 & 4.2384 & 0.01 & 0.12 & 1.2 & -0.7 & 1.6 & 94.7 \\
\hline
\end{tabular}

size relations of GK. Foote and duToit (1969) approximated GK's $V_{\mathrm{t}}$ data set with an $N_{\mathrm{th}}$ degree polynomial of the form

$V_{0}(D)=\sum_{j=0}^{N} A_{j} D^{j}$

where $D$ is the drop diameter (mm) and $A_{j}$ are constant values determined by using a least-squares curve fitting technique. We use $N=9$ and $A_{j}$ values from Table 1 of Foote and duToit (1969), which yield an approximation with errors of less than $0.5 \%$ over the size range $1.2-5.8 \mathrm{~mm}$ and $2 \%$ over the size range of $0.1-1.2 \mathrm{~mm}$. Compared to other common empirical approximations of GK's $V_{\mathrm{t}}$ (e.g., Atlas et al., 1973), which have larger velocity discrepancies for small drops $(<0.5 \mathrm{~mm})$, the expressions of Eq. (1) by increasing $N$ can give much higher accuracy over a wide range of drop sizes.

For the present experiment, DFS measurements were taken at an altitude of $\sim 375 \mathrm{~m}$ (mean sea level), with a slightly lower air density than that of the standard atmo- sphere; therefore, some velocity adjustments are required for the GK data set due to the effect of air density. Following Foote and duToit (1969), a mathematical approximation with the correction factor of air density can be expressed as

$V_{\mathrm{t}}(D)=V_{0}(D) \times\left(\frac{\rho_{o}}{\rho}\right)^{0.4}$,

where $\rho_{o}$ is the air density of the standard atmosphere $\left(\sim 1.2 \mathrm{~kg} \mathrm{~m}^{-3}\right)$ and $\rho$ is the air density at the level of observation. The reason why we used Eq. (2) is that its expression is simpler and provides adequate accuracy. Compared to a more complicated formula of $V_{\mathrm{t}}$ proposed by Beard (1976), there was a very small difference, especially for larger drops $(>1 \mathrm{~mm})$ with a velocity difference of only $0.06-0.7 \%$. The air density for each of the analyzed water drops was calculated based on the Vaisala thermodynamic measurements taken at their corresponding photographed time. The density exponent of 0.4 in Eq. (2) is currently the most widely accepted value for adjusting sea level $V_{\mathrm{t}}$ (Atlas et al., 1973; Sangren et al., 1984). The velocity errors from the predic- 


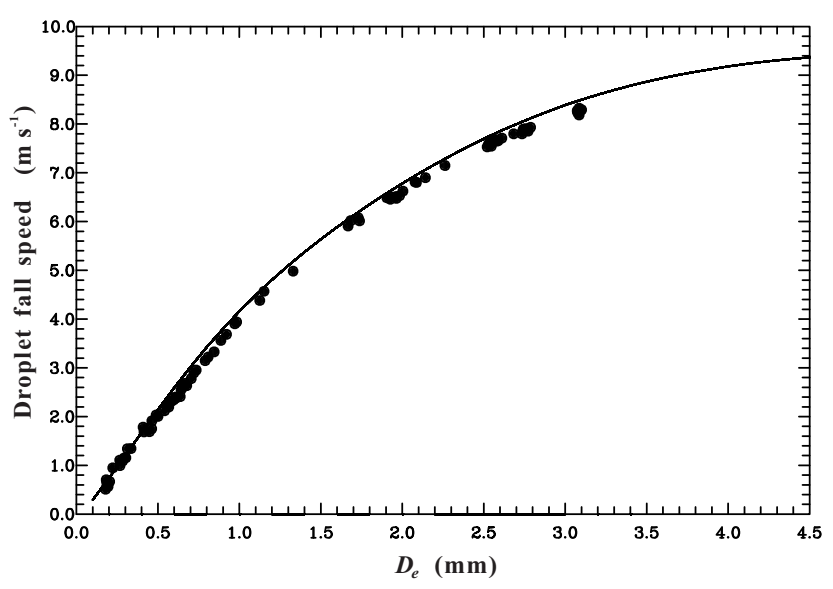

Figure 6. Size and velocity distribution of 95 analyzed drops collected from the indoor experiment. Each black dot represents a drop. The theoretical curve of $V_{\mathrm{t}}$ (Eq. 2) is also superposed on the analysis figure.

tions of Eq. (2) are within $2.5 \%$ over the size range of 3.38$5.95 \mathrm{~mm}$ (Foote and duToit, 1969). Because of a general lack of actual $V_{\mathrm{t}}$ measurements taken at altitudes above sea level, the optimum magnitude of the density exponent in Eq. (2) has been debated and may vary slightly with drop diameters from 0.4 to 0.45 for the size range of the present analysis (Beard, 1985). However, this range of the density exponent only produces a minor difference $(\sim 0.5 \%)$ in velocity adjustment at the experimental altitude and thus could be considered negligible in this study.

\section{Quantitative comparisons}

The size and velocity distribution of 95 analyzed drops are presented in Fig. 6. For comparison, the theoretical $V_{\mathrm{t}}$ curve drawn from Eq. (2) is superposed onto Fig. 6. It is clear that the HSC-observed velocities (sizes) for these drops closely follow or are immediately adjacent to the $V_{\mathrm{t}}$ curve. The differences in velocity between the HSC and theoretical values are overall minor and within $0.3 \mathrm{~m} \mathrm{~s}^{-1}$. The specific accuracy of the HSC-observed DFS $(V)$ for a given drop with a diameter $D$ may be evaluated by calculating the velocity deviation $\left(V_{\mathrm{d}}\right)$ from its corresponding theoretical $V_{\mathrm{t}}$ value. This relationship can be expressed as

$V_{\mathrm{d}}=V-V_{\mathrm{t}}(D)$.

If the HSC is assumed to have a perfect size determination (i.e., $D_{\mathrm{e}}$ (the equivalent diameter of the drop as described in Sect. 3) is equal to $D), V_{\mathrm{d}}$ can be calculated directly from Eq. (3). However, in realistic situations, some errors in the size determination may occur. In this case, determining $V_{\mathrm{d}}$ is not completely straightforward because the value of the theoretical $V_{\mathrm{t}}$ in Eq. (3) would be somewhat biased by the presence of size errors. To take this uncertainty into account,
Eq. (3) may be rewritten as

$V_{\mathrm{d}}=V-V_{\mathrm{t}}\left(D_{\mathrm{e}}+\Delta D\right)$,

where $\Delta D$ is the error in the drop size. Because $\Delta D$ is expected to be much less than $D_{\mathrm{e}}$, Eq. (4) may be further written as

$V_{\mathrm{d}}=V-V_{\mathrm{t}}\left(D_{\mathrm{e}}\right)-\frac{\partial V_{\mathrm{t}}}{\partial D} \times \Delta D$,

$V_{\mathrm{d}}=V_{\mathrm{e}}+V_{\mathrm{s}}$

$V_{\mathrm{e}}=V-V_{\mathrm{t}}\left(D_{\mathrm{e}}\right) V_{\mathrm{s}}=-\frac{\partial V_{\mathrm{t}}}{\partial D} \times \Delta D$,

where $V_{\mathrm{e}}$ is the difference between $V$ and the corresponding $V_{\mathrm{t}}$ at $D_{\mathrm{e}}$ and can be calculated directly from the HSC measurements, and $V_{\mathrm{s}}$ represents the contribution of the size error $(\Delta D)$ to the velocity deviation $\left(V_{\mathrm{d}}\right)$. It is clear from Eq. (6) that the presence of $\Delta D$, if any, will lead to the departure of $V_{\mathrm{e}}$ from $V_{\mathrm{d}}$.

The values of $V_{\mathrm{e}}$ calculated for all analyzed water drops and the percentiles with the normalization of their corresponding terminal velocities are illustrated in Fig. 7. Shading in the figure represents the range of the velocity uncertainty (i.e., $V_{\mathrm{s}}$ in Eq. 6) due to the size error of $\Delta D, \pm 0.040$ $0.045 \mathrm{~mm}$, as described in Sect. 3. Note that the size error is exclusively related to the limitation of the image resolution and does not consider other sources of errors such as the asymmetric modes of large drops due to oscillation and collision (Szakáll et al., 2010, 2014). However, this uncertainty would be relatively minor because the drops captured by the HSC in the indoor experiment is expected to reach terminal velocities with equilibrium-shaped status. The range of velocity uncertainty due to size determination increases with decreasing drop size. As evident in Eqs. (5) and (6), this is a consequence of the exponential nature of the $V_{\mathrm{t}}-D$ theoretical curve with a steeper slope at smaller drop sizes (cf. Fig. 6). The analysis indicates that $V_{\mathrm{e}}$ values are generally small and most of them range from 0.1 to $-0.2 \mathrm{~m} \mathrm{~s}^{-1}$ (Fig. 7a). In addition, except for a few of the smaller drops, the HSC-observed DFSs tend to be lower than the theoretical $V_{\mathrm{t}}$ values with typical negative $V_{\mathrm{e}}$ of -0.1 to $-0.2 \mathrm{~m} \mathrm{~s}^{-1}$ (Fig. 7a). This consistent trend may suggest a common existence of slightly positive bias in the size determination (i.e., overestimate of corresponding theoretical $V_{\mathrm{t}}$ value).

For $D_{\mathrm{e}}>\sim 1 \mathrm{~mm}$, an average magnitude of the $V_{\mathrm{e}}$ percentile is only $1.86 \%$ and the $V_{\mathrm{s}}$ percentile in Eq. (6) is similarly very small (within $0.5-3 \%$ ) (Fig. $7 b$ ). The $V_{\mathrm{e}}$ percentiles tend to increase with decreasing drop size but they are generally close to or inside the envelope of the velocity uncertainty due to size determination (Fig. 7b). The mean magnitudes of $V_{\mathrm{e}}$ percentile for $0.5<D_{\mathrm{e}}<1 \mathrm{~mm}$ and $D_{\mathrm{e}}<0.5 \mathrm{~mm}$ are calculated to be 6.3 and $6.1 \%$, respectively. For $0.5<D_{\mathrm{e}}<1 \mathrm{~mm}$, the average magnitudes of the upper and lower bounds of the velocity error (i.e., $V_{\mathrm{d}}$ in Eq. 6) 

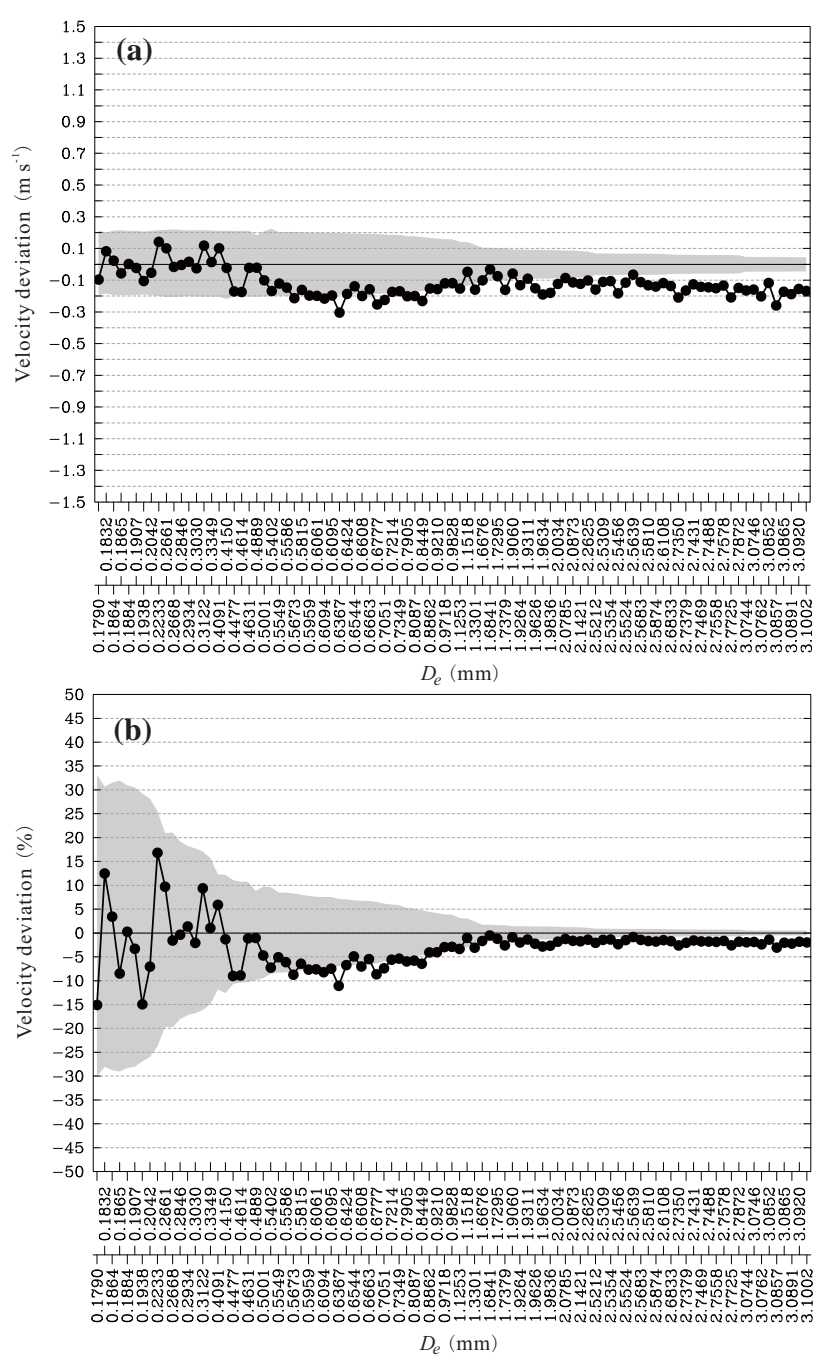

Figure 7. Velocity error analysis of the HSC-observed DFSs for all analyzed drops. Solid curve with black dot in (a) and (b) indicates, respectively, the $V_{\mathrm{e}}$ values (i.e., the difference between the HSC-observed DFS and theoretical $V_{\mathrm{t}}$ ) and their percentiles (i.e., normalized by their corresponding $V_{\mathrm{t}}$ at $\left.D_{\mathrm{e}}\right)$. Shading highlights the range of velocity uncertainties (i.e., $V_{\mathrm{S}}$ in Eq. 6) due to the potential size error $\Delta D \pm 0.040-0.045 \mathrm{~mm}$ associated with the HSC measurements.

are calculated to be 1.3 and $12.8 \%$, respectively. For $D_{\mathrm{e}}$ $<0.5 \mathrm{~mm}$, they are equal to 20.6 and $20.5 \%$, respectively. For all analyzed drops, the mean magnitudes of $V_{\mathrm{e}}$ percentile and the upper and lower bounds of the velocity error are calculated to be $4.1,5.6$, and $9.7 \%$, respectively.

The results above demonstrate that the HSC-observed DFSs are satisfactorily accurate compared to current optical disdrometers for measuring DFS with typical velocity errors of 10-25\% (Löffler-Mang and Joss, 2000; Barthazy et al., 2004). The comparison between HSC and PARSIVEL size and velocity measurements for 14 of the larger raindrops $(D>1.75 \mathrm{~mm})$ illustrates the quantization of the PARSIVEL

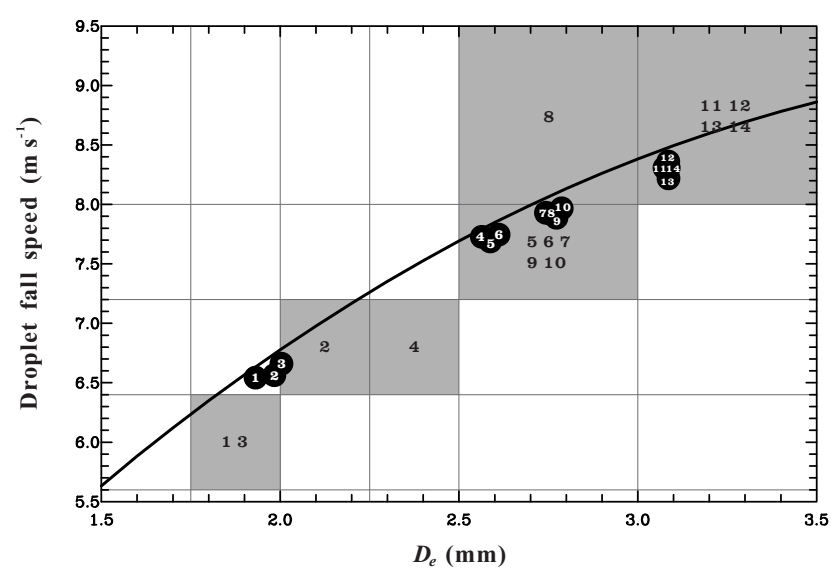

Figure 8. Size and velocity distribution of 14 water drops that were observed simultaneously by both HSC and PARSIVEL. Each drop is distinguished with labeled digits from 1 to 14 . HSC-observed velocities (sizes) are indicated by solid black circles with white digits and the PARSIVEL measurements are indicated by shading with black digits. The theoretical curve of $V_{\mathrm{t}}$ is also superposed on the analysis figure.

measurements (Fig. 8). These drops are selected for presentation because they were simultaneously observed by both the HSC and the PARSIVEL. It should be noted that in our indoor experiment, the larger drops (>2 mm), such as the 14 drops, were generated by using hypodermic needles as described in Sect. 2 . They were released one by one with some time $(\sim 10 \mathrm{~s})$ in between, corresponding to each sampling duration of PARSIVEL. Therefore, when a drop was measured by HSC (i.e., passing through the focal plane) at a certain time, it is practical to check whether the drop was also captured by PARSIVEL at that time. For smaller drops $(<2 \mathrm{~mm})$, they were generated by the sprinkling method so it is almost impossible to identify a specific drop captured by HSC from a large population of drops within each sampling interval of PARSIVEL. For clarity, each drop has been labeled with digits from 1 to 14 in Fig. 8. Within the PARSIVEL sensor precision, the two instruments agree on both size and velocity for 9 out of the 14 drops. For drops 1-4 and 8, the PARSIVEL places the drops into an adjacent size and/or fall speed bin interval to what would be expected based on the more precise HSC measurements. However, the sample size is too small to determine whether these are random or bias errors within the PARSIVEL instrument.

\section{Outdoor experiments}

The capability of investigating DFSs associated with natural rainfall using the HSC was tested outdoors in the open area of the CCU campus during the summer afternoon showers on 15 August 2013 and 25 June 2014. Photographic settings adopted in the outdoor experiment were basically similar to those of the indoor experiment. Some waterproof 
covers were required to protect the HSC and light source from wetting. Owing to the splash problem that usually occurs as precipitation particles hit the waterproof cover, a longer focal distance is basically required for outdoor applications. However, this setting would result in a larger view frame (i.e., larger pixel size) and thus less accuracy of HSC measurements. To retain the pixel resolution and to mitigate the splash problem, a teleconverter and three extension tubes were used, which allowed a longer distance $(\sim 4 \mathrm{~m})$ of the focal zone from the lens of HSC. In addition to the Vaisala weather transmitter (WXT520), a three-axis ultrasonic anemometer was employed closely adjacent to the HSC at the experimental site to provide synchronous highresolution wind information (sampling rate of $1(0.1) \mathrm{s}$ for the 2013 (2014) case) with the HSC measurements. The ultrasonic anemometer can resolve the three-dimensional wind components in centimeters per second (Siebert and Muschinski, 2001). The meteorological conditions during the outdoor experiment were observed to exhibit light winds, ranging from $\sim 0.3$ to $\sim 2.1 \mathrm{~m} \mathrm{~s}^{-1}$, and average temperature, pressure, and relative humidity were equal to $25.5^{\circ} \mathrm{C}, 960.6 \mathrm{mb}$, and $86 \%$, respectively.

The analysis procedures of determining drop size and velocity for the outdoor experiment generally follow those described in Sect. 3. Because of differences in the degree of indoor and outdoor brightness, the statistical relationship between the brightness difference and the gradient of brightness (cf. Fig. 3) is also calculated herein, and a threshold value of 35 for the brightness difference is obtained to identify the drop surface for the outdoor experiment. A complication to measurements outside is that the influence of ambient winds causes natural water drops to fall into the view frame of HSC from different angles. For example, a falling drop with motion in a direction perpendicular to the focal plan will feature transition from blurred to clear images (vice versa) within the view frame. To solve this problem, multiple cameras with different viewing angles may be deployed in the future, in a manner similar to the instrumental design of the so-called MASC described in Garrett et al. (2012). Figure 9 shows a sequence of images photographed as one natural water drop initially was out of the focal zone and then approached and moved into the focal area. In this circumstance, only part of the drop trajectory that is well inside the focal zone (highlighted in Fig. 9) is used for size and velocity calculation.

A total of 29 in-focus natural water drops with different sizes from $\sim 0.2$ to $\sim 4.2 \mathrm{~mm}$ were collected during the experiment and their velocity distributions are illustrated in Fig. 10. In contrast to the indoor DFS measurements closely following the theoretical $V_{\mathrm{t}}$ curve (cf. Fig. 6), appreciable velocity departures of these natural drops from the $V_{\mathrm{t}}$ values are evident. To elaborate whether these velocity deviations are related to the influence of ambient winds and/or turbulences, the horizontal wind speed, vertical velocity, turbulent kinetic energy (TKE), and rainfall rate measured at a time corresponding to each analyzed drop are summarized in Ta-

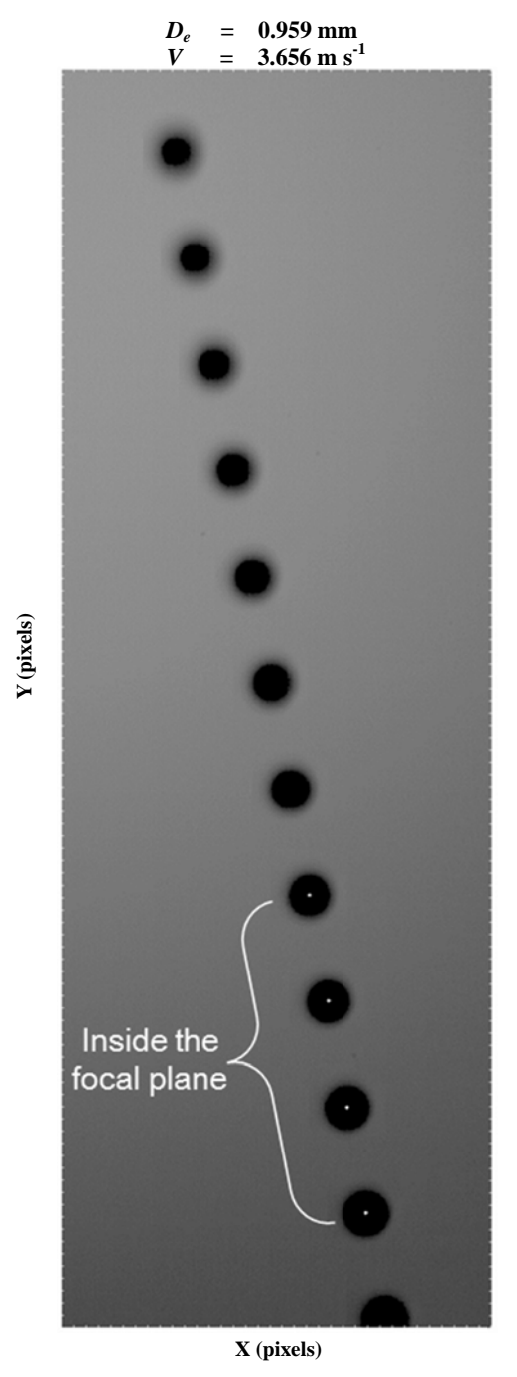

Figure 9. Multiple sequences of the photographed images for a selected natural water drop $\left(D_{\mathrm{e}}=0.96 \mathrm{~mm}\right)$ as it was initially out of the focal area with blurred drop outline in the upper portion of the view frame and then moved into the focal zone with sharp and clear drop outline in the lower portion of the view frame.

ble 1. In the TKE calculation, the turbulent part is defined as a deviation of measured air velocities from their mean values calculated over a time period of $10 \mathrm{~min}$. The calculated $V_{\mathrm{e}}$ values and percentiles are shown in Fig. 11a and b, respectively. In these analyses, each drop has been labeled with digits from 1 to 29 for clarity and discussion.

The analysis reveals that velocity deviations ${ }^{2}$ from the theoretical values of $V_{\mathrm{t}}$ vary from drop to drop range from -1.2 to $0.5 \mathrm{~m} \mathrm{~s}^{-1}$ (Fig. 11a, Table 1). The several drops collected on 25 June 2014 at 15:13:03 UTC when the rain rate was $94.7 \mathrm{~mm} \mathrm{~h}^{-1}$ and the TKE $\sim 1.6 \mathrm{~m}^{2} \mathrm{~s}^{-2}$ indicate a

\footnotetext{
${ }^{2}$ Velocity deviations (instead of velocity errors) are stated herein because the theoretical $V_{\mathrm{t}}$ value may not be a perfect ground-truth velocity reference for complicated outdoor environment.
} 


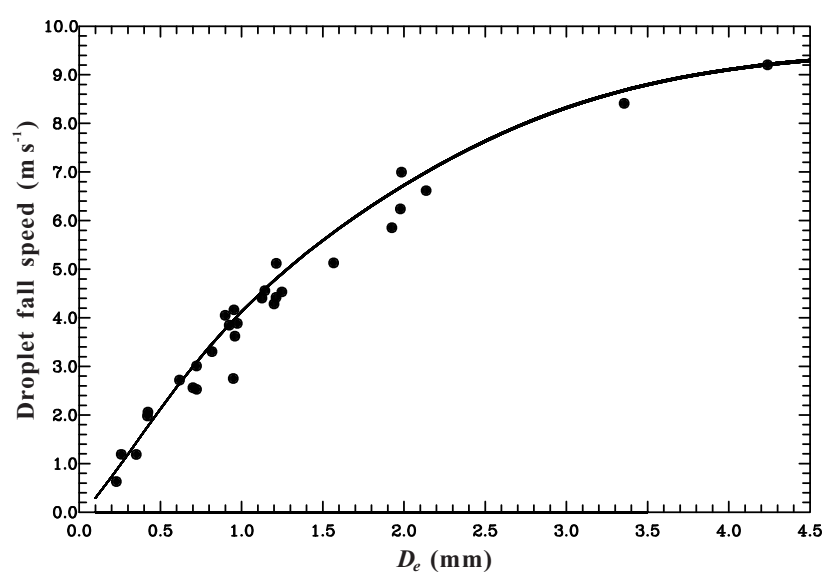

Figure 10. As in Fig. 6 but showing 29 analyzed drops collected from the outdoor experiments.

distribution that includes both positive (drop numbers 2, 5 , $11,14,21$, and 26) and negative/near-zero (drop numbers 3,18 , and 29) deviations from the expected values for still air. Montero-Martínez et al. (2009) suggested that when large drops are present, super terminal speeds can occur related to the collision-breakup-relaxation process. The largest deviation from expected value $(\sim 30 \%)$ is drop 13 , which coincided with a rain rate of $0.3 \mathrm{~mm} \mathrm{~h}^{-1}$, TKE $=1.9 \mathrm{~m}^{2} \mathrm{~s}^{-2}$, and a relatively stronger wind speed $\left(\sim 2 \mathrm{~m} \mathrm{~s}^{-1}\right)$. For other drops obtained in conditions of lower TKE, there is also a range of both positive and negative deviations. Our limited data suggest complicated behavior of natural DFSs in the turbulent environment (Pinsky and Khain, 1996; Pruppacher and Klett, 1997).

Because the number of our analyzed drops obtained outdoors is limited, we cannot make any firm conclusions regarding the statistical characteristics of natural DFS, and the results presented above may just represent a preliminary assessment of potential outdoor applications for HSC. These initial analyses indicate gaps in our knowledge of how ambient winds and turbulence impact natural DFS, which can be explored with future use of the HSC to collect larger data sets of drop images over a wider spectrum of drop sizes and environmental conditions. It is noteworthy that the velocity measurements of HSC are expected to possess good reliability because they are derived on the basis of tracking individual, specific raindrops (Testik et al., 2006). Various sampling uncertainties can be effectively mitigated in the proposed highspeed imaging technique.

\section{Conclusions}

How to accurately measure droplet fall speed in natural outdoor conditions has been a long-standing and highly challenging issue in the meteorological community. Designs of the past and current measurement techniques of raindrop fall speed outdoors predominantly involve indirect methods and
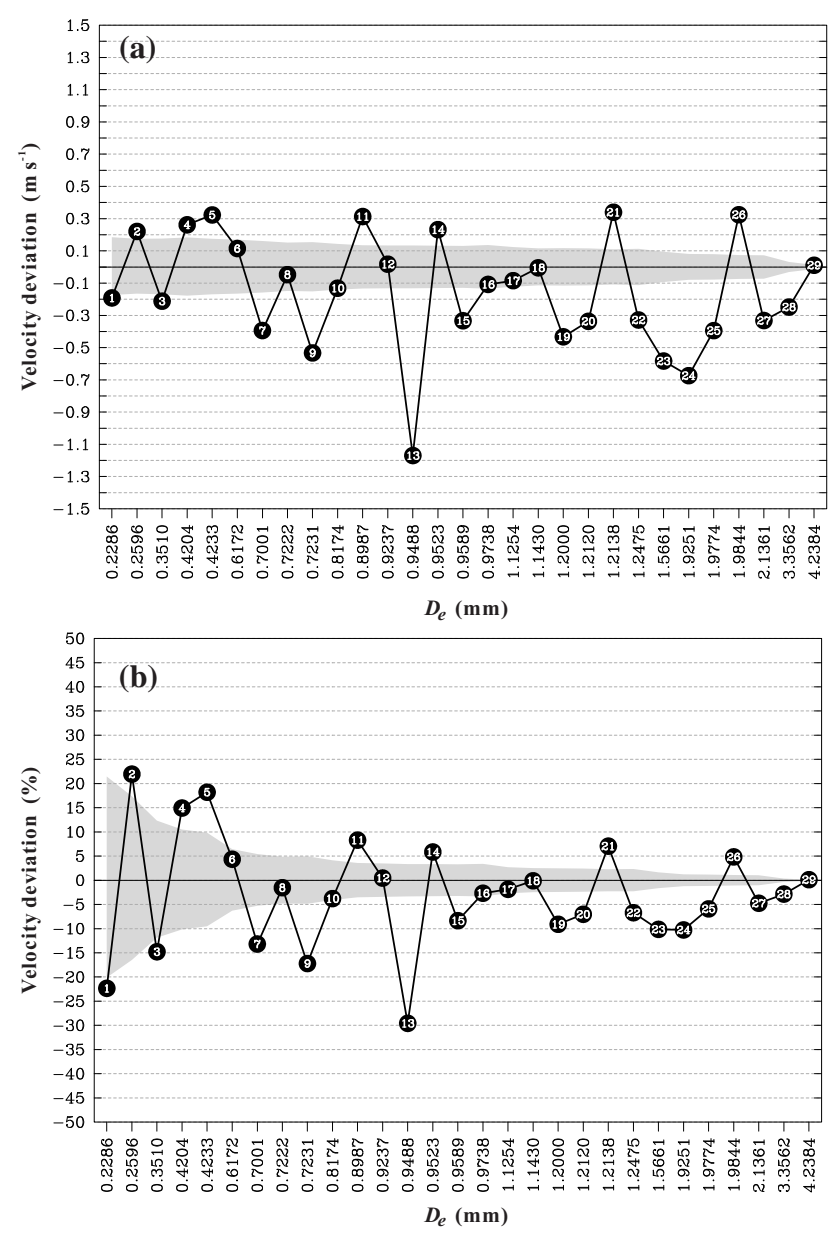

Figure 11. As in Fig. 7 but showing $V_{\mathrm{e}}$ values and percentiles of the HSC-observed DFSs for analyzed natural drops. For clarity and discussion, each drop has been labeled with digits from 1 to 29 .

usually suffer from a wide variety of sampling uncertainties and assumptions implicit in the instrumental algorithms required for automatic determination of drop sizes and velocities. Evaluation of a HSC setup based on an indoor experiment shows that our high-speed imaging technique can provide accurate fall speed measurements with a mean error of $4.1-9.7 \%$ for typical sizes of rain and drizzle drops compared to the Gunn and Kinzer (1949) empirical size-fall speed relationship. Outdoor observations during summer afternoon showers demonstrate the capability of investigating natural raindrop fall speeds using the HSC and indicate a potential role for ambient flow and turbulence on contributing to large velocity deviations from the theoretical values of terminal velocity (Pinsky and Khain, 1996). Because the HSC measurements, as presented in this article, are analyzed on the basis of tracking individual, specific raindrops, the application of the proposed HSC technique to the retrieval of fall speed information would not be hampered by various sampling uncertainties and assumptions usually found in the 
widely adopted optical disdrometers. Future collection of a large data set of particle images over a wide spectrum of drop sizes and environmental conditions using the HSC will be useful in improving understanding of how ambient winds and turbulence influence natural fall speeds of raindrops.

Acknowledgements. The authors would like to thank Chih-Han Peng, Wen-Hsuan Chen, Shiau-Ru Lin, Fang-Ting Li, Yi-Shan Liao, and Yu-Jen Lien for their assistance with the experimental work. The authors also thank two anonymous reviewers for providing helpful comments that improved the manuscript. This study was supported by the Ministry of Science and Technology of Taiwan under research grant MOST103-2111-M-002-011-MY3. This material is based upon work supported by the United States National Science Foundation under grant no. AGS 1347491 (Yuter).

Edited by: S. Malinowski

\section{References}

Atlas, D., Srivastava, R. C., and Sekhon, R. S.: Doppler radar characteristics of precipitation at vertical incidence, Rev. Geophys. Space GE, 11, 1-35, doi:10.1029/RG011i001p00001, 1973.

Barthazy, E., Göke, S., Schefold, R., and Högl, D.: An optical array instrument for shape and fall velocity measurements of hydrometeors, J. Atmos. Ocean. Tech., 21, 1400-1416, doi:10.1175/15200426(2004)021<1400:AOAIFS>2.0.CO;2, 2004.

Battaglia, A., Rustemeier, E., Tokay, A., Blahak, U., and Simmer, C.: PARSIVEL snow observations: a critical assessment, J. Atmos. Ocean Tech., 27, 333-344, doi:10.1175/2009JTECHA1332.1, 2010.

Beard, K. V.: Terminal velocity and shape of cloud and precipitation drops aloft, J. Atmos. Sci., 33, 851-864, doi:10.1175/15200469(1976)033<0851:TVASOC>2.0.CO;2, 1976.

Beard, K. V. Simple altitude adjustments to raindrop velocities for Doppler radar analysis, J. Atmos. Ocean Tech., 2, 468-471, doi:10.1175/1520-0426(1985)002<0468:SAATRV>2.0.CO;2, 1985.

Blanchard, D. C.: The behavior of water drops at terminal velocity in air, Trans. Amer. Geophys. Union, 31, 836-842, doi:10.1029/TR031i006p00836, 1950.

Cannon, T. W.: High-speed photography of airborne atmospheric particles, J. Appl. Meteorol., 9, 104-108, doi:10.1175/15200450(1970)009<0104:HSPOAA>2.0.CO;2, 1970.

Chowdhury, M. N., Testik, F. Y., Hornack, M. C., and Khan, A. A.: Free fall of water drops in laboratory rainfall simulations, Atmos. Res., 168, 158-168, doi:10.1016/j.atmosres.2015.08.024, 2016.

Cotton, W. and Gokhale, N. R.: Collision, coalescence, and breakup of large water drops in a vertical wind tunnel, J. Geophys. Res., 72, 4041-4049, doi:10.1029/JZ072i016p04041, 1967.

Donnadieu, G.: Comparison of results obtained with the VIDIAZ spectropluviometer and the Joss-Waldvogel rainfall disdrometer in a "rain of a thundery type", J. Appl. Meteorol., 19, 593-597, doi:10.1175/1520-0450(1980)019<0593:COROWT>2.0.CO;2, 1980.
Doviak, R. J. and Zrnić, D. S.: Doppler Radar and Weather Observations., 2nd edn. Academic Press, San Diego, CA, USA, 562 pp., 1993.

Foote, G. B. and duToit, P. S.: Terminal velocity of raindrops aloft, J. Appl. Meteorol., 8, 249-253, doi:10.1175/15200450(1969)008<0249:TVORA>2.0.CO;2, 1969.

Friedrich, K., Higgins, S., Masters, F. J., and Lopez, C. R.: Articulating and stationary PARSIVEL disdrometer measurements in conditions with strong winds and heavy rainfall, J. Atmos. Ocean Tech., 30, 2063-2080, doi:10.1175/JTECH-D-12-00254.1, 2013.

Fukada, M. and Fujiwara, T.: Photographic analysis on the impact of raindrops on the water's surface, Trans. JSIDRE, 143, 21-29, doi:10.11408/jsidre1965.1989.143_21, 1989.

Garrett, T. J., Fallgatter, C., Shkurko, K., and Howlett, D.: Fall speed measurement and high-resolution multi-angle photography of hydrometeors in free fall, Atmos. Meas. Tech., 5, 26252633, doi:10.5194/amt-5-2625-2012, 2012.

Ghadiri, H.: Raindrop impact and splash erosion, Encyclopedia of Soil Science, 2, 1428-1432, doi:10.1081/E-ESS, 2006.

Gunn, R. and Kinzer, G. D.: The terminal velocity of fall for water droplets in stagnant air, J. Meteorol., 6, 243-248, doi:10.1175/1520-0469(1949)006<0243:TTVOFF>2.0.CO;2, 1949.

Hauser, D., Amayenc, P., Nutten, B., and Waldteufel, P.: A new optical instrument for simultaneous measurement of raindrop diameter and fall speed distributions, J. Atmos. Ocean Tech., 1, 256-269, doi:10.1175/15200426(1984)001<0256:ANOIFS>2.0.CO;2, 1984.

Houze Jr., R. A.: Cloud Dynamics, Academic Press, San Diego, CA, USA, 573 pp., 1993.

Jones, B. K. and Saylor, J. R.: Axis ratios of water drops levitated in a vertical wind tunnel, J. Atmos. Ocean Tech., 26, 2413-2419, doi:10.1175/2009JTECHA1275.1, 2009.

Jones, B. K., Saylor, J. R., and Bliven, L. F.: Single-camera method to determine the optical axis position of ellipsoidal drops, Appl. Optics., 42, 972-978, doi:10.1364/AO.42.000972, 2003.

Kruger, A. and Krajewski, W. F.: Two-dimensional video disdrometer: a description, J. Atmos. Ocean Tech., 19, 602-617, doi:10.1175/1520-0426(2002)019<0602:TDVDAD>2.0.CO;2, 2002.

Laws, J. O.: Measurement of the fall velocity of water drops and raindrops, Trans. Amer. Geophys. Union, 22, 709-721, doi:10.1029/TR022i003p00709, 1941.

Lenard, P.: Über Regen, Meteorol. Z., 21, 248-262, 1904.

Licznar P., Łomotowski, J., Błoński, S., and Ciach, G. J.: Microprocessor field impactometer calibration: do we measure drops' momentum or their kinetic energy?, J. Atmos. Ocean Tech., 25, 742-753, doi:10.1175/2007JTECHA938.1, 2008.

Löffler-Mang, M. and Joss, J.: An optical disdrometer for measuring size and velocity of hydrometeors, J. Atmos. Ocean Tech., 17, 130-139, doi:10.1175/15200426(2000)017<0130:AODFMS>2.0.CO;2, 2000.

Magono, C., Kikuchi, K., Nakamura, T., and Kimura, T.: An experiment on fog dispersion by the use of downward air current caused by the fall of water drops, J. Appl. Meteorol., 2, 484-493, doi:10.1175/1520-0450(1963)002<0484:AEOFDB>2.0.CO;2, 1963. 
Montero-Martínez, G., Kostinski, A. B., Shaw, R. A., and GarcíaGarcía, F.: Do all raindrops fall at terminal speed?, Geophys. Res. Lett., 36, L11818, doi:10.1029/2008GL037111, 2009.

Niu, S., Jia, X., Sang, J., Liu, X., Lu, C., and Liu, Y.: Distributions of raindrop sizes and fall velocities in a semiarid plateau climate: convective versus stratiform rains, J. Appl. Meteorol. Clim., 49, 632-645, doi:10.1175/2009JAMC2208.1, 2010.

Parodi, A. and Emanuel, K.: A theory for buoyancy and velocity scales in deep moist convection, J. Atmos. Sci., 66, 3449-3463, doi:10.1175/2009JAS3103.1, 2009.

Pinsky, M. B. and Khain, A. P.: Simulations of drop fall in a homogeneous isotropic turbulent flow, Atmos. Res., 40, 223-259, doi:10.1016/0169-8095(95)00047-X, 1996.

Pruppacher, H. R. and Klett, J. D.: Microphysics of Clouds and Precipitation, 2nd edn., Springer, 954 pp., doi:10.1007/978-0-30648100-0, 1997.

Pruppacher, H. R. and Pitter, R. L.: A semi-empirical determination of the shape of cloud and rain drops, J. Atmos. Sci., 28, 86-94, doi:10.1175/1520-0469(1971)028<0086:ASEDOT>2.0.CO;2, 1971.

Rogers, R. R. and Yau, M. K.: A Short Course in Cloud Physics, 3rd edn., Pergamon Press, New York, USA, 284 pp., 1989.

Sangren, K. L., Ray, P. S., and Walker, G. W.: A comparison of techniques to estimate vertical air motions and raindrop size distributions, J. Atmos. Ocean Tech., 1, 152-165, doi:10.1175/15200426(1984)001<0152:ACOTTE>2.0.CO;2, 1984.

Schmidt, W.: Eine unmittelbare bestimmung der fallgeschwindigkeit von regentropfen, Sitz. Akad. Wiss. Wien. Mathem.-naturw. Klasse, 118, 71-84, 1909.

Schönhuber, M., Urban, H. E., Poiares Baptista, P. P. V., Randeu, W. L., and Riedler, W.: Weather radar versus 2D-video-distrometer data, in: Weather Radar Technology for Water Resources Management, edited by: Bragg Jr., B. and Massambani, O., Unesco Press, Uruguay, 159-171, 1997.

Siebert, H. and Muschinski, A.: Relevance of a tuningfork effect for temperature measurements with the Gill Solent HS ultrasonic anemometer-thermometer, J. Atmos. Ocean Tech., 18, 1367-1376, doi:10.1175/15200426(2001)018<1367:ROATFE>2.0.CO;2, 2001.
Szakáll, M., Mitra, S. K., Diehl, K., and Borrmann, S.: Shapes and osillations of falling raindrops - A review, Atmos. Res., 97, 416425, doi:10.1016/j.atmosres.2010.03.024, 2010.

Szakáll, M., Kessler, S., Diehl, K., Mitra, S. K., and Borrmann, S.: A wind tunnel study of the effects of collision processes on the shape and oscillation for moderate-size raindrops, Atmos. Res., 142, 67-78, doi:10.1016/j.atmosres.2013.09.005, 2014.

Testik, F. Y., Barros, A. P., and Bliven, L. F.: Field observations of multimode raindrop oscillations by high-speed imaging, J. Atmos. Sci., 63, 2663-2668, doi:10.1175/JAS3773.1, 2006.

Thurai, M., Bringi, V. N., Petersen, W. A., and Gatlin, P. N.: Drop shapes and fall speeds in rain: Two contrasting examples, J. Appl. Meteorol. Clim., 52, 2567-2581, doi:10.1175/JAMC-D12-085.1, 2013.

Wang, P. K. and Pruppacher, H. R.: Acceleration to terminal velocity of cloud and raindrops, J. Appl. Meteorol., 16, 275-280, doi:10.1175/1520-0450(1977)016<0275:ATTVOC>2.0.CO;2, 1977.

Yu, C.-K. and Cheng, L.-W.: Radar observations of intense orographic precipitation associated with Typhoon Xangsane (2000), Mon. Weather Rev., 136, 497-521, doi:10.1175/2007MWR2129.1, 2008.

Yu, C.-K. and Cheng, L.-W.: Distribution and mechanisms of orographic precipitation associated with Typhoon Morakot (2009), J. Atmos. Sci., 70, 2894-2915, doi:10.1175/JAS-D-12-0340.1, 2013.

Yuter, S. E., Kingsmill, D. E., Nance, L. B., and Löffler-Mang, M.: Observations of precipitation size and fall speed characteristics within coexisting rain and wet snow, J. Appl. Meteorol. Clim., 45, 1450-1464, doi:10.1175/JAM2406.1, 2006. 